\title{
Learning to Write Together Using Groupware
}

\author{
Alex Mitchell, Ilona Posner and Ronald Baecker \\ Dynamic Graphics Project, University of Toronto \\ 10 Kings College Road \\ Toronto, ON M5S 1A1, CANADA \\ Tel: 1-416-978-5473 \\ E-mail: alex@dgp.toronto.edu
}

\begin{abstract}
Most studies of collaborative writing have focused on mature writers who have extensive experience with the process of writing together. Typically, these studies also deal with short, somewhat artificial tasks carried out in a laboratory, and thus do not extend over a period of time as real writing usually does.

This paper describes an ethnographic study of collaborative writing by two groups of 4 grade six students using synchronous collaborative writing software for one hour per week over a 12 week period. Despite initially having little appreciation of what it means to write together, and no experience in synchronous collaborative writing, both groups produced nearly one dozen short collaboratively conceived, written, and edited documents by the end of the study.
\end{abstract}

A careful analysis of video tape records, written documents, questionnaires, and interviews demonstrated the importance of concepts such as awareness, ownership, and control in the writing process, and highlighted many examples of strengths and weaknesses in the writing software.

KEYWORDS: CSCW, groupware, group work, collaborative writing, learning to write, novice writers, ethnography.

\section{INTRODUCTION}

Writing together is difficult. We have been carrying out research designed to advance our understanding of how people write together, how they learn to write together, and what kinds of computer-based tools could aid this process $[1,11,14,19,20]$. Other investigators have also studied how groups write together [2, 5, 9]. Most of these studies tend to take the form of surveys or questionnaires, and have largely focused on mature writers. However, some have dealt with collaborative writing in the classroom [3], identifying the difficulties facing novice writers in collaborative situations.

\footnotetext{
Proceedings CHI'95, 1995 288-295.
}

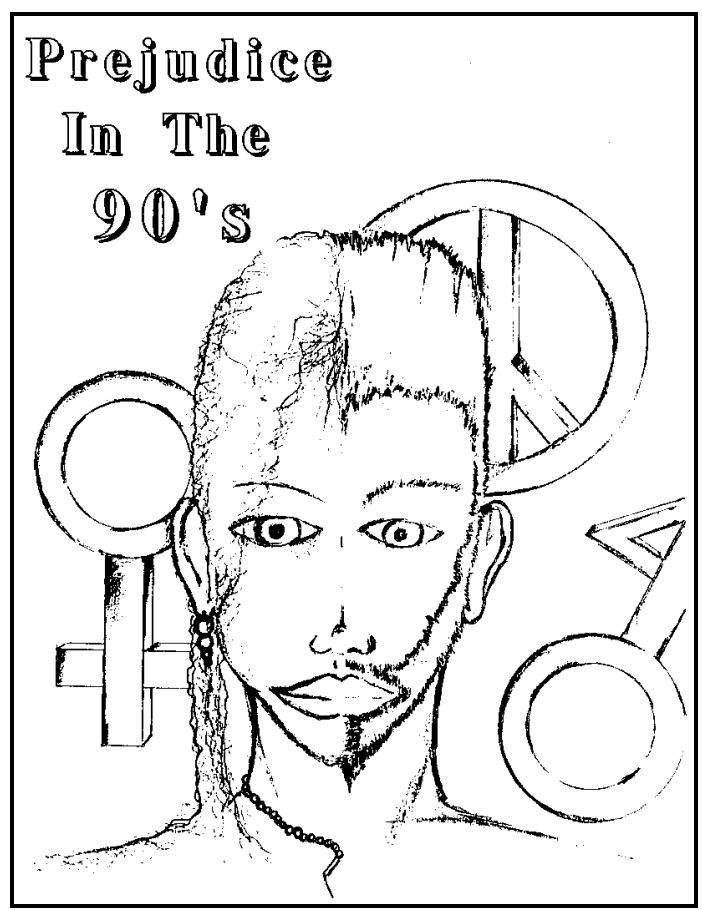

Figure 1: Cover of the magazine, by Ryan Fields, age 12.

The above research has provided insight into the collaborative writing process. A number of theories of collaborative writing have been developed $[5,20,23]$ to characterize this process. There have also been a number of tools designed to support the collaborative writing process. Most notable among the many systems are GROVE [6], PREP [16], Quilt [10], SASSE [1], and ShrEdit [17].

Studies have been conducted into the use of several of these collaborative writing tools $[12,18]$. These types of studies, while valuable, do not provide much insight into how collaborative writing tools would be used in real, extended scenarios.

Based on this previous research and our own experience with SASSE [1], we felt useful insight could be gained from a detailed study of the use of a collaborative writing tool by novice writers over an extended period of time. Although collaborative writing is a common practice, novice writers are uncertain as to how to proceed, and often have difficulty even understanding what is meant by collaborative writing. Studying the use of a collaborative writing system provides the opportunity to observe how novice writers learn to write together, and reveals much about the special needs of novice 
writers. We felt that the use of a collaborative writing tool would help with the process of learning to write together, and would give us insight into the strengths and weaknesses of the tools, providing clues as to the requirements for design of future systems.

Our study involves two groups of 4 grade six students working together to produce a magazine on prejudice (see Figure 1). Through the course of the twelve week study, they learned how to use Aspects ${ }^{1}$, a commercial synchronous collaborative editor, and developed the skills necessary to successfully write together. The students all developed different levels of expertise, and were able to share that expertise with each other to help the group accomplish its task. The study had several objectives. We wanted to observe extended use of a synchronous collaborative editor, in a situated context, with inexperienced writers, in the hope of both validating the concept of a synchronous shared editor and deriving useful insight into the design of future systems. We also wanted to see if the use of a synchronous collaborative editor would benefit the writing and learning processes.

This paper presents preliminary results of the study in the form of qualitative observations and suggestions for the design of future collaborative writing tools. We will begin by giving an overview of the study, the setup and activities involved, and the data collection and analysis methods. We will then briefly explain the way in which the students developed expertise at using Aspects and writing together. The rest of the paper will focus on the way in which the students used the collaborative writing tool, and the design recommendations that can be derived from these observations. A companion paper [21] will provide more details into the learning process, how the use of collaborative writing tools affected the product, and the impacts the experience had on the participants.

\section{THE PREJUDICE PROJECT}

The Prejudice Project took place at the Huron Street Public School in Toronto between January and May 1994. The goal of this project was for grade six students to learn about prejudice while collaboratively writing and producing a magazine on that subject.

We conducted an ethnographic study of two groups of students preparing the written material for this magazine. Eight students were selected, with the assistance of their teachers, from 14 volunteers out of two grade 5/6 classes. The students were experienced with the Computer Supported Intentional Learning Environment (CSILE) shared knowledge building system [22], but were not familiar with synchronous collaborative work on a computer.

Through the course of the study the students learned to write together using Aspects on networked Macintosh computers. Aspects allows multiple users to work concurrently on shared documents. It uses a replicated architecture, provides various locking mechanisms, and minimal consistency

\footnotetext{
${ }^{1}$ Aspects was developed by Group Technologies Inc.
}

control. It is a fairly conservative but stable system as opposed to research systems which may provide many useful features but may lack the robustness necessary for serious extended use.

\section{Study Setup}

Each group met once a week for one hour after school. The students worked in a classroom, sitting at adjacent Macintosh computers (see Figure 2). Each networked computer ran a version of Aspects, with documents shared between all machines. The students' seating arrangements were changed each week to reduce the possibility of subgroup formation and other influences of physical placement.

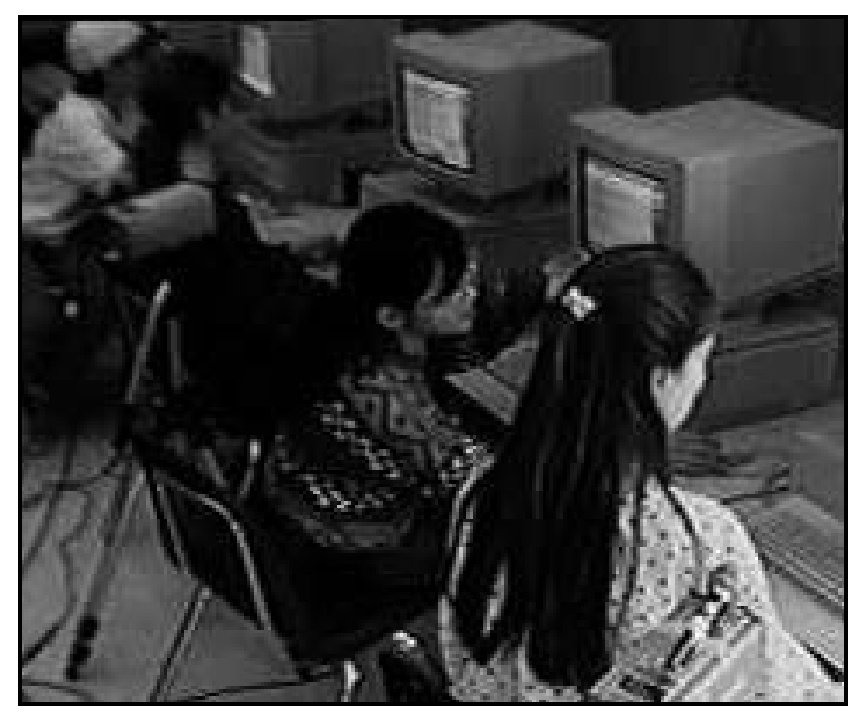

Figure 2: Physical setup of the study

During the twelve-week period, the students were given training in the use of the Aspects system, introduced to the concepts and skills necessary for collaborative writing, and then given the freedom to use those skills as they saw fit.

The first five weeks were highly structured in order to cover various topics related to prejudice. The format of group work was guided by the instructor (Ilona) in an attempt to introduce a variety of ways of working collaboratively. The activities included writing a poem and a story as a group. Students were exposed to the various mechanisms provided by Aspects, giving them the tools necessary to perform their tasks. The assigned tasks were designed to expose the students to a variety of writing styles and approaches [19, 20, 23]. They started with scribe/consultant writing, where a scribe enters text in a document, and one or more consultants provide ideas but do not actually enter them in the document. They were also given tasks involving parallel writing, with writers individually entering text at the same time in the same document, but in different regions, and joint writing, with writers working closely on one section of the document. 
In the remaining weeks the students were free to choose what they wanted to work on and how they would work together. Their work included doing research, writing articles, creating artwork, and editing some of the materials created in the first five weeks to be incorporated into the magazine.

Throughout the study, a balance had to be maintained between the amount of training given and our desire to see how the students would use the technology without guidance.

\section{Data Collection and Analysis}

During each weekly session all of the group's interactions were videotaped. The recording setup included two cameras covering the students working on the computers, and two cameras capturing screen images. In addition, time-indexed notes were made using the Timelines [7] video annotation software while the sessions were in progress.

Exploratory analysis was conducted on the video records of the sessions by two people using Timelines. This analysis identified common problems, incidents and trends in the data. More in-depth discourse analysis and coding will be done in the future to explore in detail some of the areas discussed in this paper.

A number of other measures were used to provide a rich view of the sessions. The students' teachers were asked to evaluate the students' abilities, and to provide blind evaluations of a selection of work, both individual and group. The evaluations were intended to provide information which could be used to give insight into the effects of the use of groupware technology on the students' learning experience and the quality of the document. The results from this data were used in the companion paper [21].

We also conducted a halfway and a final questionnaire and a final individual interview with each student. A few weeks after the end of the project, we came back and conducted a group discussion about the project, which gave additional insight into the students' experience.

\section{OBSERVATIONS}

As a result of the analysis of this data, we have compiled a number of observations that can be drawn from the study and contribute to the understanding of collaborative writing and collaborative writing tools. Through the process of creating their magazine, the two groups of students were confronted with a number of challenges, most notably learning to write together and learning to use the tools provided. We also observed many activities directly related to the collaborative task: awareness, ownership, and access control.

Having never worked on a group project that demanded such close collaboration, the students had to learn both what it means to write together and how to do that successfully. In addition to learning about the task of writing together, the students had to learn to use the tools provided. The students had no problem working with the computers. All had extensive experience with computers both in the classroom and at home. In fact, the students were so comfortable with the computers that they took a cruel pleasure in causing the software to crash.

The first major difference encountered by any user when moving from single-user to multi-user software is the notion of a shared space in which other people are working. This experience was illustrated in many ways. The students developed awareness of themselves and each other. Similarly they developed patterns for determining who would control the shared space. Finally, they negotiated access to that space.

\section{Learning to Write Together}

From the start, both groups were not sure how to approach the task of "writing together". When encouraged to work together, they claimed that they didn't know what this meant. When the groups first began using Aspects, they instinctively shifted into a parallel writing style, all working independently with little communication. Although they were all able to enter text into the document at the same time and see each other's entries, they weren't initially comfortable with this. It took some time for them to get used to the fact that the document was shared.

When they found that entering duplicate text without consultation didn't work very well, the group switched to a consultant/scribe mode of writing. Despite the ability to access the document synchronously, one person would do all the typing with the others suggesting ideas. This style of writing leads to interesting control and ownership problems, as will be discussed later. This form of writing most closely resembles the way groups work together synchronously using traditional technology [20], and thus involved the least adaptation on the part of the students.

Later, as they became more comfortable with the task and the system, the students began to make full use of the synchronous editing capabilities of Aspects. The following is a brief example of how the students made effective use of the shared workspace. While composing a story during the fifth week of the study, both groups used a consultant/scribe writing style. One student "drove" the writing, eliciting ideas and entering them in the document, while the others contributed ideas and followed on their own screens. However, one student frequently moved around in the document, rereading the story from the start and suggesting changes. She also pointed out errors using a telepointer. Interestingly, though, she did not actually make changes. This notion of control over the document by the scribe will be discussed further in the section on control below.

Part of the problem with the notion of what it means to write together is the question of what it means for a piece of writing to be a group document. The students weren't sure whether a document written in parallel could ever be considered a unified piece of writing. They felt that such a document should be rewritten from scratch by one person. 
This came up when the first group was editing a poem with stanzas written in parallel by each group member. ${ }^{1}$

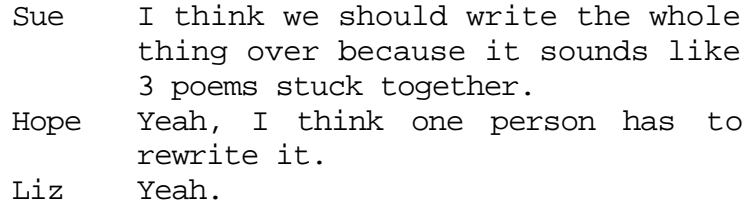

This same difficulty was encountered with several other documents that were written in parallel. It was only when a document was written jointly with one person acting as scribe that the group acknowledged that the document was coherent.

This problem faced by our novice writers highlights an ongoing question faced by researchers of collaborations: when should a document be considered to have been truly written together.

\section{Learning To Use the Technology}

Collaborative writing is a very difficult task. To support it successfully, the tools provided must not add to that complexity. Experienced writers often get distracted from the content of their writing when composing on a computer [8]. The vast number of fonts and styles available tend to encourage a focus on format and layout. This is especially true for novice writers. The students found it hard enough to stay on task without technological distractions. Tools such as chat boxes and cute telepointer shapes were often more distracting than useful. An interface that supports gradual disclosure of features would allow users to be comfortable with the system at all stages of learning (a) ${ }^{2}$.

The feedback provided by the system was often obscure and confusing, leading the students to ignore it. When the messages were critical, such as when document consistency was lost, this led to later problems (b). The fact that documents are shared, yet replicated, caused continuous confusion to both the students and the experimenters. A number of documents were lost and had to be reentered because the various contributors all assumed that someone else had saved the document. The location of the document was not at all obvious from the interface (c).

However, as the students became more familiar with the concept of shared access to a common document, they developed working patterns that took advantage of the technology. As will be discussed below, the students came to realize how the technology could be used in different situations.

\footnotetext{
${ }^{1}$ Note that the names of the students have been changed, but gender has been preserved.

2 Throughout our discussion of the study we will use letters such as (a) to link our observations to the list of design recommendations appearing near the end of this paper.
}

\section{Collaboration and Awareness}

The importance of collaborator awareness mechanisms has been well recognized $[1,4,14]$. When dealing with novice writers, this is especially important.

\section{Self-Awareness}

Even after becoming familiar with the notion of a shared workspace and having worked on the system for six weeks, the students still had difficulty determining where they were and what they were doing.

Where Am I? There are several things that the students were asking when they asked "Where am I?" The simplest is location in the shared document. However, it is also important to provide some feedback as to whether the user is in a conference or working alone, and whether the current document is private or shared with others (d).

It was common for people to become confused as to whether their work would be seen by others or not, and whether they would be able to see others' work. This was especially true when someone stopped working closely with the group, and then later returned.

In one case, it turned out that the students who had been working together to edit a document had in fact been working in separate copies of the document (e).

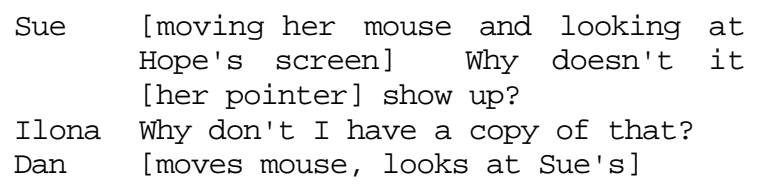

This situation wasn't discovered until Sue happened to glance at Hope's screen and notice that her telepointer was not showing up.

What Am I Doing? Similarly, in a multi-user conference with multiple documents it isn't always obvious what you are doing at a given moment. This can range from confusion as to whether you are telepointing or not, a simple interface problem, to more subtle concerns, such as whether you are interfering with someone else's attempts to edit text. The system needs to make the information about your relative location and influence on others readily available (e).

\section{Collaborator Awareness}

Collaborator awareness is always important, but even more than usual when dealing with users who are learning to work together. Awareness not only includes awareness of where people are within a document, but who is present for collaboration and who is potentially present.

Where Are You? Lack of any reminder of where others are makes it easy to forget that there is a shared workspace (f):

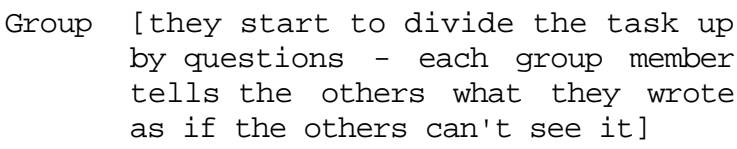




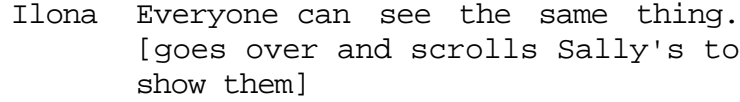

What Are You Doing? When working individually, it is easy to lose track of what others are doing. This problem is often overcome by resorting to physical pointing and glancing at each other's screens $(\mathrm{g})$ :

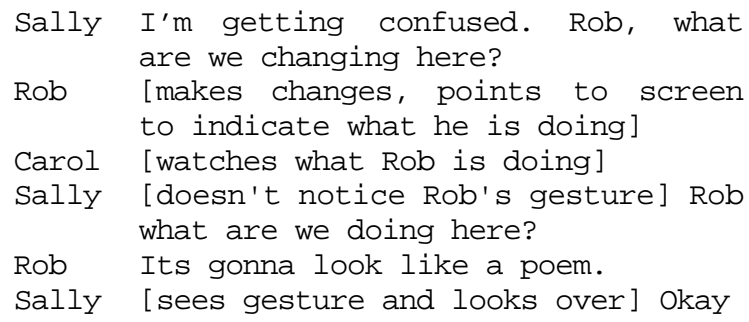

Who Did That? With synchronous shared access to the document, it is possible to enter text or to delete someone else's text without that person's knowledge. This can lead to confusion:

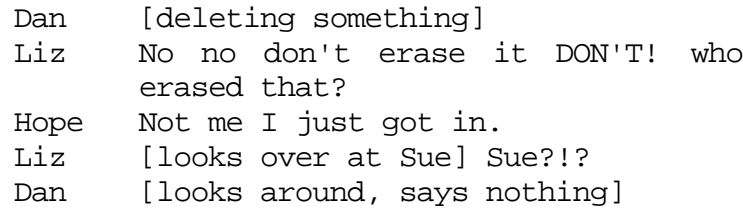

Tracking of where other people are and what they are doing can come in many forms. Aspects provides bars alone the side of the document indicating that someone has control of a region of text. This tells you that someone is there, but not who it is.

\section{Pointing and Gesturing}

Users may also want to explicitly provide information to others about their actions. Aspects provides a simple telepointing mechanism, allowing each user to gesture with a remote cursor of a user-selected shape. However, the students often found it easier to use physical pointing and gestures:

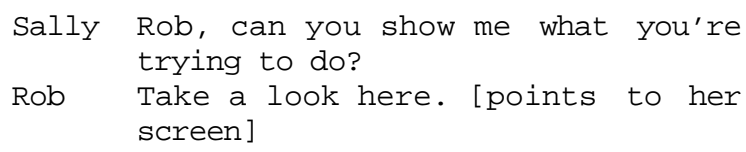

Telepointers were too limiting because they were both unable to draw collaborators' attention and lacked information about the person who was pointing. All this information is available in a simple hand gesture $(\mathrm{g})$.

The telepointers also tended to be rather distracting; the students often ended up chasing each others' pointers around the screen. However, one group did learn to use them effectively when proofreading and editing:

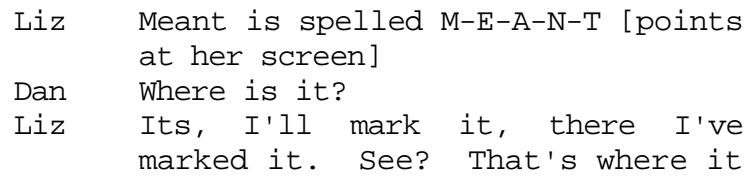

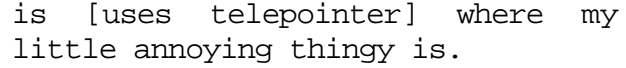

Having discovered this function, Liz explains it to the others:

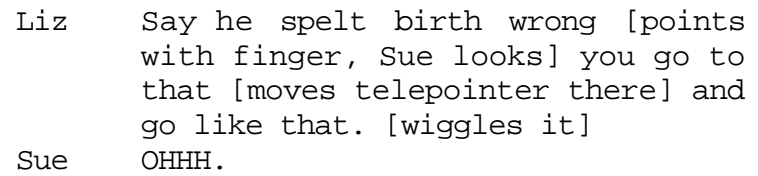

The shared workspace encourages this type of consulting and collaborative learning.

\section{Effect of Physical Placement}

The students tended to take advantage of the physical placement of the computers to aid in their awareness of group activities. The computers were placed in a row, allowing each student to glance around at the other students and at their screens. From the start, they tended to glance around a lot, anxious to stay aware of what the rest of the group is doing. This ability to look at each other's computers also led to shifts between working independently or together on separate computers and working huddled around one machine.

The physical placement of the machines also allowed people to notice when someone is looking at their work; this is useful for encouraging and facilitating collaboration and consultation:

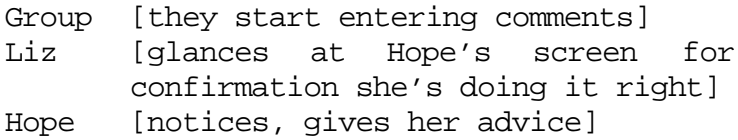

However, the physical placement can also lead to formation of subgroups and exclusion of peripheral group members. To minimize this, we rearranged seating patterns each session.

\section{Document Ownership}

The perception of who has a claim to ownership of a section of text, or over the entire document, was independent of how ownership was represented by the technology. Aspects doesn't provide any explicit indication of who wrote a section of text. However, the students would often assume, especially in the early parts of the study, that the person who typed a section was the only person who could change it.

Similarly, there was a connection between who typed in a section of text and who got credit for the ideas contained in the text. We observed that the scribe usually provided fewer ideas than the rest of the group. Despite this, the scribe occasionally took credit for the content of the document. For example, in the first group, the person who typed a story claimed the next day that it was his story:

$\begin{array}{ll}\text { Dan } & \text { I wrote the story. } \\ \text { Sue } & \text { No I did. } \\ \text { Liz } & \text { I did. } \\ \text { Hope } & \text { We all did. } \\ \text { Dan } & \text { The one about the... }\end{array}$


$\begin{array}{ll}\text { Hope } & \text { I made up Tiger Lily. } \\ \text { Ilona } & \text { I thought everybody wrote it. } \\ \text { Dan } & \text { I wrote it most cause I typed } \\ & \text { everything. }\end{array}$

Although the system did not provide explicit ownership information, the students tended to continue to identify text with the person who typed it. This showed up most clearly when the second group was editing one of the documents. In this case, the sections of the document were all written in parallel, with each section easily identifiable as belonging to a different person. Two of the group members were suggesting changes, but refused to make the final alterations until the entire group gave permission.

However, when the group was working together on a document that had already been edited, the group members had no reservations about arbitrarily deleting someone else's text without telling them $(\mathrm{h})$. This suggests that at this point the group members had come to regard the text as shared, rather than just owned by the person who typed it.

\section{Document Control}

The system's assumptions about control over the document, both in terms of the ability of group members to edit sections of text and to access documents, had several effects on the collaborative writing process

The students in the study used Aspects in paragraph locking mode. This allows each user to gain control of a paragraph of text and make changes within that paragraph. As long as the user doesn't move the selection point out of the paragraph, other users are locked out. This granularity of locking led to some interesting behaviour.

When working with physical documents, the students were able to gain control over a paper by grabbing it if necessary. In Aspects there was no way to force a shift in control. One student understood the technology to the extent that he deliberately kept an entire document as one paragraph to keep control of the changes being made to the text, even when encouraged to add paragraph breaks:

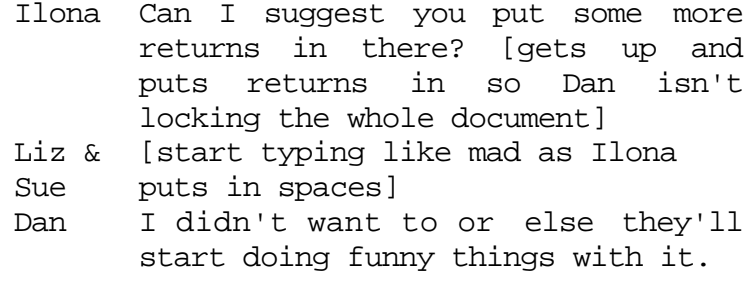

However, the group soon learned to overcome the limitations of the locking mechanism by simply using the other person's computer rather than trying to get control of the document from within the system.

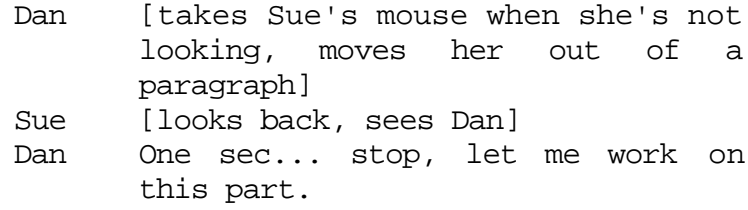

Control over the text also had an effect on the roles taken on by the group members. When deciding who would be the scribe, the group would either take a vote or argue until someone managed to get control of the text. For example, when the first group was composing a story, Dan ended up gaining control of the text. The group went along with this, everyone dictating while he types; ideas were passed around, negotiated, and the final decision was made by the scribe.

Although the system gave the scribe explicit control of the document, the other members of the group were still able to make significant contributions and provide feedback which affected the contents of the document. In the above example, where Dan had control of the document, there were several occasions where other students tried to make changes. Kim would attempt to alter a sentence, and failing that would ask Dan to make the change, using the telepointer to indicate the change. So, in spite of the control mechanisms provided by the technology, the entire group was able to influence the document (i).

\section{Synchronous Access and Collaboration}

The fact that everyone could access the workspace influenced the style of collaboration. Initially, everyone wanted to type just because they could. However, as they gained experience with the technology and with group writing, the students became more selective in their choice of writing style. For example, when working on the last day on the magazine's introduction, the second group shifted between scribe and independent parallel writing to solve a consensus problem. Sally was acting as scribe, but the group couldn't decide on the wording of one section of the document. To solve this, they all entered their own ideas, then all read them and selected the best. They then shifted back to scribe mode, and continued (h).

Working synchronously but on separate sections of the document worked well in a task that lends itself to division. On the tenth day, the two members of the first group were preparing the questions for an interview - they discussed the content, then split the task up, but talked back and forth while entering the text. Then, after the interview, they worked in a scribe fashion, one student dictating the answers while the other typed.

However, it was not always clear who had been given the role of scribe. In fact, the assignment of roles tended to change dynamically, since the technology lets anyone take control as long as the previous scribe is willing to relinquish control. In general the groups were able to adapt to this shifting of control. If someone's ideas were not being accepted or they were being ignored, that person would sometimes go off and start entering the ideas independently in a different section of the document.

The students were able to adapt their use of the system to suit their working patterns, and to take in to consideration the social and group interactions taking place as they 
worked. It was possible because the system did not attempt to impose strict roles and patterns of usage on the students (j).

\section{DESIGN RECOMMENDATIONS}

The above observations stress the importance of maintaining an awareness of both the shared space in which you are working, and the fact that there are other people working in that shared space. Dourish and Bellotti [4] indicate that the use of shared feedback, the notion of providing implicit, peripheral information about everyone in a shared space, is a promising approach. Examples of this approach can be seen in ShrEdit [12] and SASSE [14]. ShrEdit allows you to request that the system find and track movements of others; SASSE provides peripheral information in the form of colour-coded, shared scrollbars, audio cues, a document overview (or gestalt), and a tracking mode.

Another important problem introduced by collaborative tools is the need to keep track of changes in a shared document. One way to provide the necessary information about changes in the document is through the display of differences in the document, often called "diffs", either as change bars [15], through the use of annotations [14], or through more active notification [13].

Ownership of and access to the shared workspace are also important considerations. As we have seen, the way in which both of these are handled by the system have an influence on the behaviour of the group. While some systems such as Grove [6] and PREP [16] assign roles to collaborators, most systems leave this up to the group. This, along with flexible access and floor control mechanisms, allows social interactions, not the system, to determine working patterns and group behaviour.

The above discussion suggests a number of design recommendations, which we will summarize below:

(a) provide tools appropriate to the users' level of expertise; avoid distracting tools; use gradual disclosure

(b) make sure the system's feedback is simple and concise

(c) provide a clear and accurate mental model of the system

(d) provide self-awareness in terms of location in the shared workspace, and potential actions in that location

(e) provide awareness of the user's effects on others

(f) provide awareness of the presence of others in the shared workspace to encourage discussion and negotiation

(g) provide collaborator awareness in terms of shared feedback and explicit information such as gestures

(h) provide flexibility in terms of the representation of ownership information to allow for changes over time

(i) allow flexibility in terms of document control to allow for shifting roles at different stages of the writing process

(j) avoid imposing patterns on natural social interactions

\section{CONCLUSION}

The observations we have made of the students working together using Aspects are very encouraging. Over the 11 hours they were working with Aspects, they developed distinct, mature strategies for working together. Despite having never worked with synchronous collaborative writing software, both groups managed to produce coherent documents which they felt reflected the work of the entire group. Together they successfully produced a 32 page magazine which will be on display early next year as part of an exhibit at the Ontario Science Centre.

The students testified to having written the magazine "together", something that they did not even know the meaning of at the start of the study. Perhaps this in itself is the best definition of group writing - the perception that the results of your work are the result of the group's work, rather than the work of the individual members of the group. This achievement validates the concept of a synchronous shared text editor, and provides promise for the use of such technology in education and writing in general.

The group jointly learned about an important topic, prejudice. As one student said in the final group discussion:

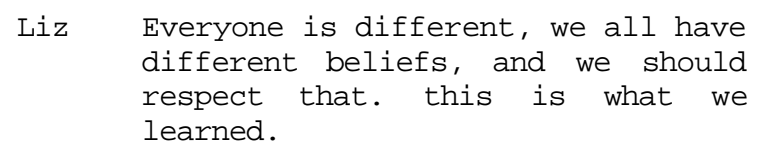

They had become comfortable with the idea of writing together, and confident with the technology. From not knowing what it means to write together, they had progressed to feeling that they were able to succeed at, and enjoy, group writing. During the final group discussion, one student volunteered the following:

Rob

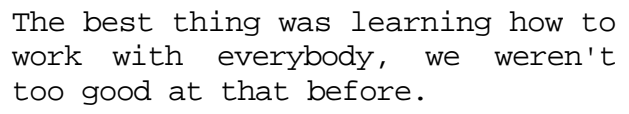

By observing this learning process, we have been able to gain an insight into the nature of group writing, and identify some of the effects of the use of collaborative writing tools on this process.

We have seen that the technology has a distinct effect on the way in which novice writers approach the collaborative writing task. However, at the same time we have seen that writers, as they become familiar with both the task and the technology, are able to exploit the features of the system and use it to their advantage in creative ways. The observations we have made of the problems students have learning to write together are very similar to those experienced seen in adult writers. From these observations we have drawn a series of recommendations for future design.

Our study stretched over twelve weeks. With a task domain as complicated and unfamiliar as collaborative writing, it is important that any observations be made over an extended period, in situ, and in a situation where users are allowed to approach their tasks as freely as possible. This allows 
usage patterns to develop naturally, and provides the time needed to learn about the task and the technology. Although this type of ethnographic study is harder to run and much more time-consuming to analyze than a traditional lab study, the type of real usage that we have observed could never be seen in a usability laboratory.

\section{ACKNOWLEDGMENTS}

The authors would like to thank the teachers and students at the Huron Street Public School for their time and enthusiasm, and the researchers at OISE, Marline Scardamalia, Peter Rowley, and Jim Hewett, for their help with the project. Ben Smith-Lea and Russell Owen provided essential technical support. Hiroshi Ishii, Sara Bly and our reviewers provided valuable comments. We would also like to thank those who provide funding for our research, especially the Natural Science and Engineering Research Council of Canada.

\section{REFERENCES}

1. Baecker, R.M., Nastos, D., Posner, I.R., and Mawby, K.L. The User-centred Iterative Design of Collaborative Writing Software, Proceedings of InterCHI'93, ACM, 1993, 399-405, 541.

2. Beck, E. A Survey of Experiences of Collaborative Writing. In Sharples, M. (Ed.), Computer Supported Collaborative Writing, Springer-Verlag, 1993.

3. DiPardo, A. and Freedman, S.W. Historical Overview: Groups in the Writing Classroom, Technical Report No. 4, Centre for the Study of Writing, University of California, Berkeley, 1987.

4. Dourish, P. and Bellotti, V. Awareness and Coordination in Shared Workspaces, Proceedings of CSCW'92, ACM, 1992, 107-114.

5. Ede, L. and Lunsford, A. Singular Texts/Plural Authors: Perspectives on Collaborative Writing. Southern Illinois University Press, 1990.

6. Ellis, C.A., Gibbs, S.J., and Rein, G.L. Groupware: Some Issues and Experiences, CACM 34(1), 1991, 3858. Reprinted in Baecker, R.,M. Readings in Groupware and Computer-supported Cooperative Work: Facilitating Human-Human Collaboration, Morgan Kaufmann, 1993.

7. Harrison, B., Owen, R., and Baecker, R.M. Timelines: An Interactive System for the Collection and Visualization of Temporal Data, Proceedings of Graphical Interface '94, Morgan Kaufmann, 1994.

8. Hass, C. Does the Medium Make a Difference? Two Studies of Writing with Pen and Paper and with Computers. Human-Computer Interaction, 4, 1989, 149-169.

9. Kraut, R.E., Egido, C., and Galegher, J. Patterns of Contact and Communication in Scientific Research Collaborations. In Galegher, J., Kraut, R.E., and Egido, C. (Eds.), Intellectual Teamwork: Social and Technological Foundations of Cooperative Work, Erlbaum, 1990, 149-171.
10. Leland, M.D.P., Fish, R.S., and Kraut, R.E. Collaborative Document Production Using Quilt, Proceedings of CSCW'88, ACM, 1988, 206-215.

11. Mawby, K. Designing Collaborative Writing Tools, M.Sc. Thesis, Department of Computer Science, University of Toronto, 1991.

12. McLaughlin Hymes, C. and Olson, G.M. Unblocking Brainstorming Through the Use of a Simple Group Editor, Proceedings of $C S C W^{\prime} 92$, ACM, 1992, 99106.

13. Minor, S., and Magnusson, B. A Model for Semi(a)Synchronous Collaborative Editing, Proceedings of ECSCW'93, 1993, 219-231.

14. Nastos, D. A Structured Environment for Collaborative Writing, M.Sc. Thesis, Department of Computer Science, University of Toronto, 1992.

15. Neuwirth, C.M., Chandhok, R., Kaufer, D.S., Erion, P., Morris, J., and Miller, D. Flexible DIFF-ing in a Collaborative Writing System, Proceedings of CSCW'92, ACM, 1992, 147-154.

16. Neuwirth, C.M., Kaufer, D.S., Chandhok, R., and Morris, J.H., Issues in the Design of Computer Support for Co-authoring and Commenting, Proceedings of CSCW 90, 183-195. Reprinted in Baecker, R.,M. Readings in Groupware and Computer-supported Cooperative Work: Facilitating Human-Human Collaboration, Morgan Kaufmann, 1993.

17. Olson, J.S., Olson, G.M., Mack, L.A., and Wellner, P. Concurrent Editing: The Group's Interface. Proceedings of Interact '90, 835-840.

18. Olson, J.S., Olson, G.M., Storrøsten, M., and Carter, M. How a Group-Editor Changes the Character of a Design Meeting as well as its Outcome, Proceedings of CSCW'92, ACM, 1992, 91-98.

19. Posner, I.R. A Study of Collaborative Writing, M.Sc. Thesis, Department of Computer Science, University of Toronto, 1991.

20. Posner, I.R. and Baecker, R.M. How People Write Together, Proceedings of the Twenty-fifth Annual Hawaii International Conference on System Sciences, 1992, 127-138. Reprinted, with slight modification, in Baecker, R.,M. Readings in Groupware and Computer-supported Cooperative Work: Facilitating Human-Human Collaboration, Morgan Kaufmann, 1993.

21. Posner, I.R., Mitchell, A., and Baecker, R.M. Learning to Write Together using Computers - Product and Experiences, submitted for review.

22. Scardamalia, M., Bereiter, C., McLean, R., Swallow, J., and Woodruff, E. Computer Supported Intentional Learning Environments, Journal of Educational Computing Research 5(1), 1989, 51-68.

23. Sharples, M., Goodlet, J.S., Beck, E.E., Wood, C.C., Easterbrook, S.M., and Plowman, L. Research Issues in the Study of Computer Supported Collaborative Writing. In Sharples, M. (Ed.), Computer Supported Collaborative Writing, Springer-Verlag, 1993, 9-28. 
